Non-isothermal calorimetric studies of the crystallization of lithium disilicate glass

\author{
C.S. Ray a, D.E. Day ", W. Huang ", K. Lakshmi Narayan " , T.S. Cull ${ }^{\text {b, }}$ \\ K.F. Kelton ${ }^{\text {h, }}$

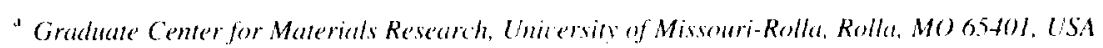 \\ "Deparment of Phasics. Washingten Linicersin. St. Loutis, MO 6.3130. USA \\ Received 18 September 1995: revised 20 March 1996
}

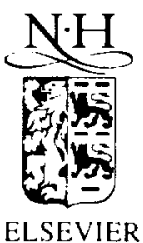




\section{JOURNAL OF NON-CRYSTALLINE SOLIDS}

A joumal on the chemical, electronic, optical, and mechanical properties of glasses, amorphous semiconductors and metals, sol-gel materials, the liquid state of these solids, and the processes by which they are formed.

Founding Editor: Professor J.D. Mackenzie

\begin{tabular}{lll}
\hline Editor: R.A. Weeks & Co-editor: D.L. Kinser & Editorial Assistant: A. Cook \\
$+1-615.3222923$ & $+1-615322.3537$ & $+1-6153222058$
\end{tabular}

Vanderbilt University, 610 Olin Hall, Nashville, TN 37240, USA

Fax: +1-615343 8645. E-mail: jncs@vuse.vanderbilt.edu

Regional Editors

G.H. Frischat. Institut für Nichtmetallische Werkstoffe, Technische Universität Clausthal, D-36878 Clausthal-Zellerfeld, Germany G.N. Greaves, Daresbury Laboratory, Daresbury, Warrington WA4 4AD, UK

H. Kawazoe, Tokyo Institute of Technology, Materials and Structures Laboratory, 4259 Nagatsuta, Midori-ku, Yokohama 226, Japan

J. Lucas, Laboratoire des Verres et Céramiques, Université de Rennes I, Ave. du Général Leclerc, Campus de Beaulieu, 35042 Rennes cedex, France

J.H. Simmons, Department of Materials Science and Engineering, University of Florida, 154A Rhines Hall, Gainesville, FL $32611-2066$. USA

Advisory Editorial Board

$\begin{array}{ll}\text { Austrulia } & \text { People's Rep. of Chinu } \\ \text { D.R. McKenzie, Sydney } & \text { Gan Fuxi, Shanghai } \\ \text { Austria } & \text { Portugal } \\ \text { J. Hafner, Vienna } & \text { R.M. Almeida, Lisbon } \\ \text { Belgium } & \text { Russia } \\ \text { G.J. Adriaenssens, Heverlee-Leuven } & \text { V.I. Arbuzov, St Petersburg } \\ \text { Brazil } & \text { O.V. Mazurin, St Petersburg } \\ \text { E.D. Zanotto, São Carlos } & \text { Sruth Korea } \\ \text { Italy } & \text { U.C. Paek, Kwangju } \\ \text { A. Montenero, Parma } & \text { Spain } \\ \text { Japun } & \text { M.T. Mora. Barcelona } \\ \text { H. Hosono, Yokohama } & \text { Sweden } \\ \text { N. Soga, Kyoto } & \text { L.M. Torell } \\ \text { K. Tanaka, Jbarahi } & \end{array}$

Taiwan

Jenn-Ming $W_{u}$, Hsinchu

Unifed Kingdom

S.R. Elliott, Cambridge

A.C. Wright, Reading

USA

S.W. Freiman, Gaithersburg, MD

D.L. Griscom, Washington, DC

K. Kelton, St Louis, MO

G.W. Scherer, Wilmington, DE

T.P. Seward III, Coming. NY

M. Tomozawa, Troy, NY

A.K. Varshneya, Alfred. NY

M.C. Weinberg, Tucson, AZ

(for complete addresses, see page 2 of the preliminary pages of issues $1 \& 2$ )

\section{Aims and Scope}

Review Articles, Research Papers, Comments and Letters on chemical, electronic, optical, mechanical, structural and fracture properties of non-crystalline materials including glasses, amorphous semiconductors, metals (alloys) and sol-gel materials which form glasses, the liquid state of all materials from which non-crystalline solids can be formed, and the processes for the formation of non-crystalline solids are accepted.

\section{Abstracted/indexed in:}

Biological Abstracts: Ceramic Abstracts; Current Contents: Engjneering. Technology and Applied Sciences; EI Compendex Plus; Engineered Materials Abstracts; Engineering Index: INSPEC: Metals Abstracts; Physics Briefs.

Subscription Information 1996

Volumes 192-207 of Journal of Non-Crystalline Solids
(ISSN 0022-3093) are scheduled for publication. (Frequency: monthly.) Prices are available from the publishers upon request. Subscriptions are accepted on a prepaid basis only and are entered on a calendar-year basis. Issues are sent by SAL (surface air lifted) mail wherever this service is available. Airmail rates are available upon request. Please address all enquiries regarding orders and subscriptions to:

Elsevier Science B.V.

Order Fulfilment Department

PO Box 211, 1000 AE Amsterdam

The Netherlands

Tel: $+31-204853642$, Fax $+31-204853598$

Claims for issues not received should be made within six months of our publication (mailing) date. If not, they cannot be honoured free of charge.

US Mailing notice - Joumal of Non-Crystalline Solids (ISSN 0022-309.3) is published monthly, except semimonthly in February, March. May, June, July, August, September and October, by Elsevier Science B.V., Molenwerf 1, P.O. Box 211, 1000 AE Amsterdam, The Netherlands. Annual subscription price in the USA is US\$ 4654 (valid in North, Central and South America only), including air speed delivery. Second class postage paid at Jamaica. NY 11431

USA Postmasters: Send changes to Journal of Non-Crystalline Solids, Publications Expediting, Inc., 20() Meacham Avenue, Elmont, NY 11(0)3. Airfreight and mailing in the USA by Publications Expediting.

The paper used in this publication meets the requirements of ANSI/NISO Z39.48-1992 (Permanence of Paper).

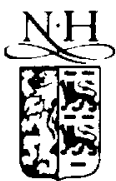




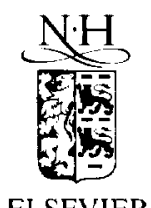

Journal of Non-Crystalline Solids $204(1996) 1-12$

\title{
Non-isothermal calorimetric studies of the crystallization of lithium disilicate glass
}

\author{
C.S. Ray ", D.E. Day ", W. Huang ", K. Lakshmi Narayan ", T.S. Cull ${ }^{\text {b, }}$ \\ K.F. Kelton ${ }^{\text {b, * }}$ \\ "Graduate Center for Materials Research, Unirersity of Missouri-Rolla, Rolla, MO 65401, USA \\ "Department of Phrsics. Washington Lnirersity, St. Louis, MO 6.31.30. USA \\ Received 18 September 1995: revised 20 March 1996
}

\begin{abstract}
The influence of preannealing treatments on the polymorphic crystallization of lithium disilicate glasses is examined. As expected, $g$ lasses heated at different rates through the temperature range where there is significant nucleation develop widely different numbers of nuclei. This can dramatically influence the stability and transformation characteristics of the annealed glass. Non-isothermal differential scanning calorimetry (DSC) and differential thermal analysis (DTA) measurements are demonstrated to be useful to probe the nucleation behavior. The first systematic investigations of particle size effects on the non-isothermal transformation behavior are presented and discussed. Based on DTA and microscopy experiments, we show that small particles of lithium disilicate glasses crystallize primarily by surface crystallization. The relative importance of surface versus volume crystallization is examined by varying particle size, by introducing nucleating agents and by exposing glasses to atmospheres of different water content. These data are analyzed quantitatively using a numerical model developed in a second paper following in this volume.
\end{abstract}

\section{Introduction}

A detailed knowledge of the temperature dependence of nucleation and growth is essential for materials design, since these processes control the phases and microstructures formed. Experimental investigations to obtain kinetic parameters, however, are laborious and time consuming, particularly for the evaluation of the nucleation rates. Differential scanning calorimetry (DSC) and differential thermal analysis (DTA) are useful techniques for studying the kinetics

Corresponding author. Tcl.: + 1.314935 6228; fax: + $1-314$ 9356219 ; e-mail: klk (o wuphys.wusil.edu. of first order phase transformations. When coupled with microscopic studies of the transformation microstructure, isothermal DSC and DTA studies can provide information about the mode and kinetics of transformation [1]. Using independent measurements of the growth velocity, it is even possible in some cases to extract kinetic information about the steady-state and time-dependent nucleation rates [2].

Non-isothermal calorimetric techniques, which sample the transformation kinetics over a range of temperatures in a single measurement, offer several advantages over isothermal methods. Studies can be made more easily in less time, smaller quantities of sample are generally required and the kinetics of transformation can be probed over a different, typi- 
cally higher, temperature range. Also, automation of non-isothermal data collection should be easier. allowing such measurements to be readily made at remote locations, such as in a microgravity environment. Non-isothermal methods, however, suffer from the lack of quantitative methods of analysis. Existing methods are based on erroneous assumptions for the temperature dependence of the effective rate constants, generally resulting in misinformation about the transformations [3-5].

Here, we present results obtained from non-isothermal DTA studies of lithium disilicate glass, which is known to crystallize polymorphically by homogeneous nucleation. A method for probing the temperature range for significant nucleation is presented and critiqued. Most methods for the analysis of calorimetric data assume infinitely large samples, while DTA and DSC samples generally consist of small particles. By studying ensembles of particles of different sizes and by deliberately introducing nucleating agents to enhance the internal nucleation rate, several effects due to finite particle size are demonstrated, including an increased importance of surface crystallization. All experimental data are analyzed qualitatively here. In a companion paper [6], we will develop a realistic numerical model and use that model to analyze these data more quantitatively. The results from that analysis support the general conclusions presented here.

\section{Experimental procedure}

$\mathrm{Li}_{2} \mathrm{O} \cdot 2 \mathrm{SiO}_{2}$ (LS2) glass was prepared by melting a well-mixed $50 \mathrm{~g}$ batch of the appropriate composition in a platinum crucible at $1475^{\circ} \mathrm{C}$ for $3 \mathrm{~h}$ in air, and subsequently casting the melt between two steel plates. Before casting, the melt was stirred periodically (30 to $40 \mathrm{~min}$ interval) with a silica rod to ensure homogenization of the glass. X-ray diffraction (XRD) and examination by scanning electron microscopy (SEM) showed no evidence of unmelted or crystalline particles in the as-quenched glass. The silica content in the glass was determined using energy dispersive $X$-ray analysis (EDAX). The intensity (in counts/s) of the $\mathrm{Si}$ peak in the glass was compared with that determined from a silica standard. using identical beam currents and scan areas.
Based on 12 different locations, each $\sim 100 \mu \mathrm{m} \times$ $100 \mu \mathrm{m}$, the average silica content of the glass was within $1.5 \mathrm{w} \%$ of that in the batch. The quenched glass was ground and screened to five different particle diameters, 25-45, 75-106, 180-300, 425500 and $850-1190 \mu \mathrm{m}$. These five different ranges are designated by the approximate average size in each range: $35,90,240,462$ and $1020 \mu \mathrm{m}$. The powdered glasses were stored in a vacuum desiccator until used for differential thermal analysis (DTA) measurements.

Nucleation and growth of the crystal phase in the glass powders were investigated using a PerkinElmer DTA-1700 equipped with a computer interface for storing and analyzing the thermal data. All measurements were made on approximately $40 \mathrm{mg}$ samples using platinum containers for both glass and reference (alumina) samples. Some DSC measurements were made using a Perkin-Elmer DSC-7 with stainless steel sample pans. Both the DTA and the DSC were calibrated prior to and periodically during the measurements for all the heating rates used in the present investigation, using $\mathrm{In}, \mathrm{Zn}$ and $\mathrm{Al}$ standards. Nitrogen with a flow rate of $50 \mathrm{~cm}^{3} / \mathrm{min}$ was used in the DTA measurements, while argon flowing at 30 $\mathrm{cm}^{3} / \mathrm{min}$ was used in the DSC.

The crystal nucleation rate in LS2 glass is significant only between $425^{\circ} \mathrm{C}$ and $500^{\circ} \mathrm{C}[7,8]$. Non-isothermal DTA studies of the effects of heating at different rates through this nucleation zone were made using the $462 \mu \mathrm{m}$ average diameter glass particles. The LS2 glass was first heated at a high heating rate $\left(\sim 80^{\circ} \mathrm{C} / \mathrm{min}\right)$ from room temperature to $400^{\circ} \mathrm{C}$. After stabilizing at $400^{\circ} \mathrm{C}$ for approximately $5 \mathrm{~min}$, the glasses were heated at different heating rates $\left(\Phi_{\mathrm{n}}=0.5,1,2,4,6,10\right.$ and $\left.15^{\circ} \mathrm{C} / \mathrm{min}\right)$ to $500^{\circ} \mathrm{C}$, and subsequently heated at $15^{\circ} \mathrm{C} / \mathrm{min}$ (the crystallization heating rate, $\Phi_{c}$ ) until the crystallization was complete. To explore the effects of the crystallization heating rate, these measurements were repeated for $\Phi_{\mathrm{c}}=2,4,6,10$ and $15^{\circ} \mathrm{C} / \mathrm{min}$.

The effects of particle size on the crystallization kinetics of the LS2 glass were investigated by heating as-quenched glass particles of different sizes (detailed above) in the DTA at $15^{\circ} \mathrm{C} / \mathrm{min}$ from room temperature until the completion of crystallization. No pre-nucleation treatments were used for this investigation. As will be demonstrated, this provides 
information on the mechanism of crystallization (surface and/or internal). To investigate possible changes in the crystallization with the introduction of heterogeneous nuclei, similar measurements were repeated for different particles of the LS2 glass containing 0.001 and $0.005 \mathrm{wt} \%$ platinum. The platinum was introduced into the glass by adding a $\mathrm{PtCl}_{4}$ solution to the original glass batch. This was then melted and quenched in the same manner as for the undoped LS2 glass.

To further elucidate the relative roles of surface versus volume crystallization, samples made from three different particle sizes of the as-quenched LS2 glass were exposed to a closed, moist atmosphere of $100 \%$ relative humidity for $80 \mathrm{~h}$ (wet samples) before being scanned in the DTA. These results were compared with those from DTA scans of samples made from as-quenched glass particles of the same size, that were dried at $120^{\circ} \mathrm{C}$ for $80 \mathrm{~h}$ (dry samples) and then scanned in the DTA.

\section{Results and discussion}

DSC /DTA crystallization peaks can be characterized by three parameters, the maximum peak height, $(\delta T)_{p}$, the peak full width at half maximum $\left(\Delta T_{p}\right)$ and the peak temperature, $T_{p}$. Often attention is given only to $T_{p}$. When properly analyzed as a function of scan rate, for example, shifts in $T_{\mathrm{p}}$ are generally believed to provide information about the activation energy for the transformation $[9,10]$, although the general validity of this technique has been questioned [3-5]. A decrease in the peak temperature with increased preannealing time has also been used to explain the observed decrease in the glass stability due to an increase in the number of internal nucleation sites resulting from the annealing treatment. As we will show here and in the companion paper [6], the additional peak parameters can also provide important information about nucleation and growth. Studies of the complete peak profile, for example, can often reveal features about the mode of crystallization and the evolving microstructure that are not manifest in the peak temperature alone. In this section we present the changes in the peak profile parameters for the crystallization of lithium disilicate glass under non-isothermal conditions as a function of preannealing treatment, particle size and the density of nucleating agents.

\subsection{Non-isothermal nucleation}

The solid circles in Fig. 1 show the dependence of the maximum height of the DTA crystallization peak. $(\delta T)_{p}$ on $\Phi_{n}$, the rate of heating from $400^{\circ} \mathrm{C}$ and $500^{\circ} \mathrm{C}$. As discussed in Section 2, these data were taken from an ensemble of LS2 glass particles with an average diameter of $462 \mu \mathrm{m}$; the crystallization heating rate, $\Phi_{c}$, was $15^{\circ} \mathrm{C} / \mathrm{min}$ for all glasses. For this glass. $(\delta T)_{\mathrm{p}}$ decreases precipitously with increasing $\Phi_{n}$, up to about $3^{\circ} \mathrm{C} / \mathrm{min}$. Little change is observed for heating rates faster than $3^{\circ} \mathrm{C} / \mathrm{min}$. These DTA results can be explained qualitatively from previous observations [8] that $(\delta T)_{p}$ scales with the initial number of nuclei in the glass. Glasses heated more slowly through the nucleation zone will form more nuclei. Were the nucleation rate at its steadystate value, the number of nuclei formed would be inversely proportional to the scan rate. As will be demonstrated in our companion paper [6], however, time-dependent nucleation plays a more important role for these studies; the number of nuclei generated

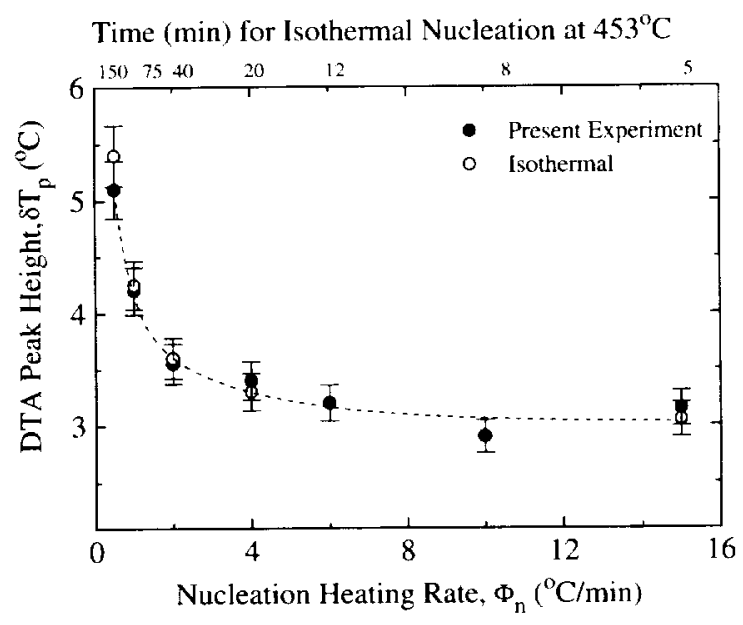

Fig. 1. A comparison between the DTA peak heights for the crystallization of samples of LS2 glass powders $(425-500 \mu \mathrm{m}$ diameter) that were either heated nonisothermally through the nucleation zone (O) or annealed isothermally at the peak nucleation temperature $(O)$. Following this nucleation treatment, all samples were heated at $15^{\circ} \mathrm{C} / \mathrm{min}$ through the crystallization peak. 
then is not so simply related to the scan rate. A constant value of $\delta T_{\mathrm{r}}$ for $\Phi_{\mathrm{n}}>3^{\circ} \mathrm{C} / \mathrm{min}$ indicates that the number of new nuclei generated as a result of the scan through the nucleation zone is not significant compared with those already present in the as-quenched glass. In those cases, the transformation proceeds primarily by growth on quenched-in nuclei and by surface crystallization (which is shown to be important later). The critical value, $\Phi_{11}{ }^{*}$, above which no significant number of new nuclei form in a glass may have practical significance as a characteristic property of a glass of a given particle size prepared under specified conditions. A knowledge of this value would be useful for designing the proper heat treatment for that glass to fit specific applications, where development of nuclei in the glass is either required or must be suppressed.

The open circles in Fig. 1 show the values of $(\delta T)$, measured previously [8] for the same LS2 glass as a function of isothermal hold time at $453^{\circ} \mathrm{C}$ (top axis). This is the experimentally determined temperature for the maximum nucleation rate in LS2 glass $[7,8]$. The heating rate used for crystallization after completion of the isothermal hold at $453^{\circ} \mathrm{C}$ was the same $\left(15^{\circ} \mathrm{C} / \mathrm{min}\right)$ as was used to obtain the data indicated by the solid circles in Fig. 1. The nucleation times at $453^{\circ} \mathrm{C}$ scale with $\Phi_{n}$. producing nearly identical values of $(\delta T)$, in the two cases. This suggests that the duration of an isothermal anneal at the peak nucleation temperature required to produce a result that is identical to a scan experiment can be calculated simply by computing the time required to scan between $425^{\circ} \mathrm{C}$ and $500^{\circ} \mathrm{C}$, the range where the measured steady-state nucleation rate is significant. This is a surprising result given the strong temperature dependence of the steady-state nucleation rate near the peak, although similar behavior has been assumed on cooling [11.12]. An analysis of the time-dependent nucleation behavior is required for an explanation; this is presented in our companion paper [6]. Briefly, the nucleation rate in the asquenched glass is depressed significantly below the steady-state value [13]. During the DSC/DTA heating, the nucleation rate rises above the steady-state value, but at a temperature higher than the peak in the steady-state nucleation rate [5]. Anneals of longer duration in the nucleation zone produce a more complete relaxation to the steady-state cluster distri- bution with a resulting increase in the nucleation rate and a smaller displacement of the nucleation peak to higher temperatures. Taken together, this complicated scenario results in a greater number of nuclei for slower scans or longer isothermal anneals and produces the observed DTA results. Therefore, the validity of the earlier speculation $[11,12]$ has been justified experimentally in the present investigation and is explained quantitatively in terms of the timedependent nucleation behavior [6]. While these experimental results provide proof for the predictions made based on numerical modeling [5], they also demonstrate that a simple interpretation of DSC / DTA data to obtain quantitative information of the nucleation rate is not possible. As is discussed in this paper, however, it remains possible to gain some qualitative insight into the transformation process, provided that microstructural information is also included in the model.

As is illustrated in Fig. 2, a similar functional dependence of the DTA peak height on nucleation heating rate is observed for different crystallization heating rates, $\Phi_{c}$. The magnitudes of the values of $(\delta T)_{p}$ for each $\Phi_{n}$, however, increase with increasing $\Phi_{c}$. In this case those $\delta T_{\mathrm{p}}$ corresponding to $\Phi_{\mathrm{c}}=$ $15^{\circ} \mathrm{C} / \mathrm{min}$ are approximately $1.5 \times$ larger than for $\Phi_{c}=10^{\circ} \mathrm{C} / \mathrm{min}$, almost exactly equal to the ratios of the crystallization heating rates. Since the temperature difference between the sample and reference pan

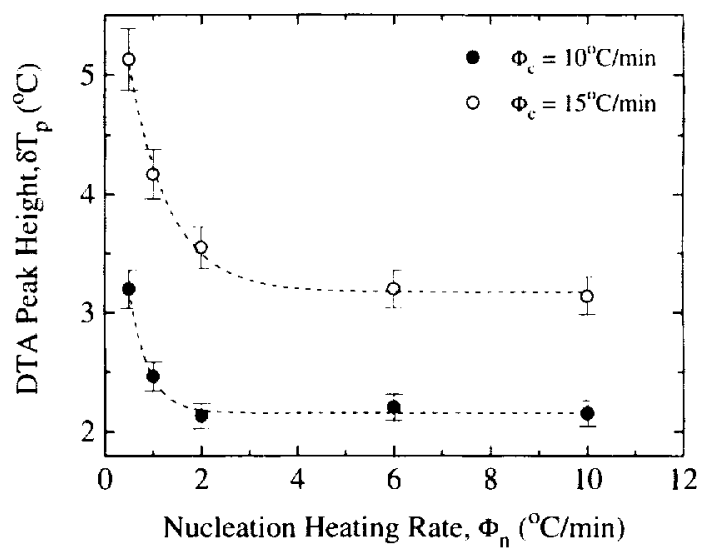

Fig. 2. DTA peak height for the crystallization of LS2 glass powders (425-500 $\mathrm{\mu m}$ diameter) as a function of heating rate through the nucleation zone for two different values of crystallization scan rate $\left(\Phi=10^{\circ} \mathrm{C} / \mathrm{min}\right.$ and $\left.15^{\circ} \mathrm{C} / \mathrm{min}\right)$. 
is proportional to the rate of heat released, which is in turn proportional to the rate of phase transition, this proportionality arises because the phase transition takes place at a higher temperature for the more rapidly scanned sample. The growth velocity is laster there and will transform the sample more quickly, resulting in a faster rate of heat release and a correspondingly larger DSC/DTA signal.

As mentioned earlier, non-isothermal calorimetric measurements are often analyzed to determine an effective activation energy, $E$, for the glass to crystal transformation. The model most frequently used is due to Kissinger [10], which relates $E$ to the dependence of the peak temperature, $T_{p}$, with the heating rate, which should be the crystallization heating rate, $\Phi_{c}$, in our experiments,

$\ln \left[\frac{T_{p}^{2}}{\Phi_{c}}\right]=\frac{E}{R T_{p}}+$ constant

$R$ is the gas constant. A plot of $\ln \left(T_{\mathrm{p}}^{2} / \Phi_{\mathrm{c}}\right)$ versus $1 / T_{\mathrm{p}}$ should then yield a straight line with slope $E / R$. The use of Eq (1) to determine $E$ has been criticized [3-5]; it is believed to yield a value of $E$ that has a little physical significance for transformations involving both nucleation and growth [5]. It has been demonstrated both experimentally $[14,15]$ and theoretically [5], however, that $E$ is approximately equal to the activation energy for crystal growth over the range of the DTA peak temperatures, provided that the glass sample is saturated with nuclei prior to crystallization in DTA. In this case, no significant additional nucleation occurs and the transformation proceeds by growth only. This condition can be achieved (1) by using glass powders of extremely small particle size $(<50 \mu \mathrm{m}$ in diameter $)$, so that the number of surface nuclei greatly exceeds the number of volume nuclei formed during the DTA scan, or (2) by nucleating the glass at the temperature corresponding to the maximum nucleation rate for a considerable time (e.g., $8-10 \mathrm{~h}$ in many glasses) prior to crystallization in DTA $[14,15]$, ensuring that relaxation to the steady-state distribution is complete and that the fraction of new volume nuclei forming during the scan is inconsequential.

Kissinger plots for the LS2 glass scanned non-isothermally at different heating rates through the nucleation zone are shown in Fig. 3. A range of $\Phi_{n}$

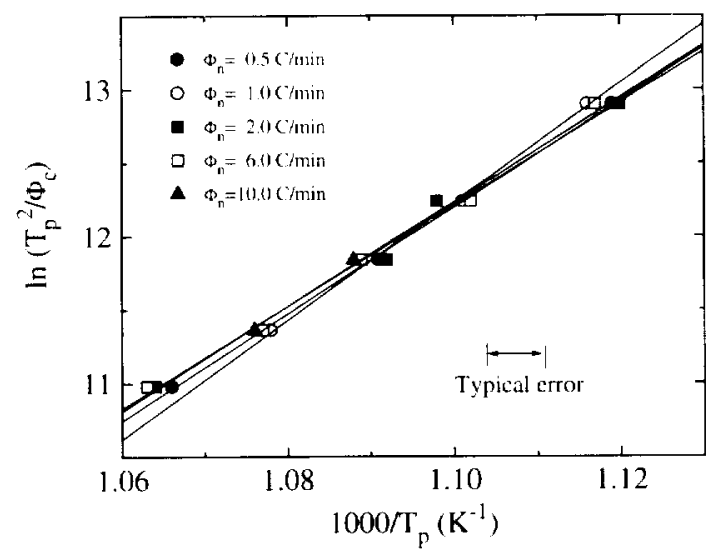

Fig. 3. Kissinger plot for several values of $\Phi_{n}$ and $\Phi_{i}$. Curves correspond $t o, D_{c}=2,4,6,10$ and $15^{\circ} \mathrm{C} / \mathrm{min}$. The probable error in $1000 / T_{p}$ is indicated by the error bar; the error in $\ln \left(T_{p}^{2} / \Phi_{C}\right)$ is of order the size of data symbols.

were used; for each $\Phi_{n}, \Phi_{c}=2,4,6,10$ and $15^{\circ} \mathrm{C} / \mathrm{min}$. All plots are linear, as predicted by $\mathrm{Eq}$. (1), and are almost indistinguishable, implying that the activation energy for the transformation is independent of $\Phi_{n}$. The average value of the activation energy, $E=299 \pm 15 \mathrm{~kJ} / \mathrm{mol}$, compares well with the measured activation enthalpy for crystal growth, $E_{\mathrm{i}} \approx 282 \mathrm{~kJ} / \mathrm{mol}$ [16]. Based on Fig. I, the glasses nucleated at slower heating rates $\left(<3^{\circ} \mathrm{C} / \mathrm{min}\right)$ contained a much larger number of nuclei than the glasses nucleated at rates $>3^{\circ} \mathrm{C} / \mathrm{min}$. That the activation energies of transformation are independent of $\Phi_{n}$ is due to the separation between the peaks in the nucleation and growth curves for this glass. The transformation temperature for the glass is well above the temperature range for which significant nucleation occurs (even taking into account the transient effects), and no significant number of new nuclei apparently form during the transformation of the glass. The calorimetric signal is then dominated by crystal growth on the pre-existing fixed number of nuclei.

The DTA peak width, $(\Delta T)_{\Gamma}$, defined as the width of the DTA crystallization peak at half-maximum, is predicted to be a qualitative measure for the dimensionality of the transformation, $n,[17]$,

$n=2.5 R\left(\frac{T_{\mathrm{p}}^{2}}{\Delta T_{\mathrm{p}} E}\right)$. 


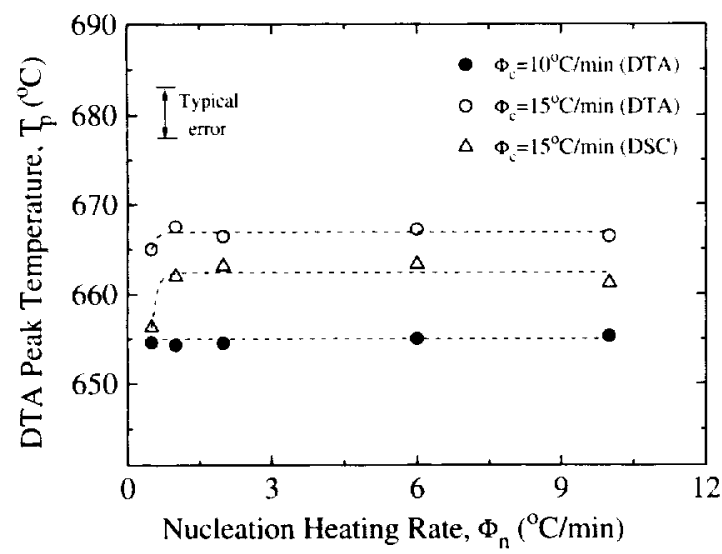

Fig. 4. DTA and DSC peak temperatures for the crystallization of LS2 glass powders $(425-500 \mu \mathrm{m}$ diameter) as a function of heating rate through the nucleation zone for two different values of crystallization scan rate $\left(\Phi_{c}=10^{\circ} \mathrm{C} / \mathrm{min}\right.$ and $\left.15^{\circ} \mathrm{C} / \mathrm{min}\right)$.

A value of $n$ close to 3 suggests bulk or three dimensional crystal growth and a value close to $I$ is consistent with surface growth. Intermediate values of $n$ between 1 and 3 might result if both surface and internal crystallization were occurring. Such arguments should, of course, be taken only as suggestive; more complicated reactions might mimic the predicted behavior. Quantitative models of the phase transition should always be supported by direct microscopic investigations of the transformation microstructure, as was done here (cf. Fig. 7). In this relatively simple case of a known polymorphically crystallizing glass, however, Eq. (2) can be used to assess the relative importance of the surface versus volume contribution to the phase transformation, provided that the temperature dependence of $E$ is small.

In Fig. 4, the DTA crystallization peak temperature, $T_{p}$, is shown as a function of $\Phi_{11}$ for two different crystallization scan rates, $\Phi_{c}=10$ and $15^{\circ} \mathrm{C} / \mathrm{min}$, for the LS2 glass. For comparison, DSC data taken at $\Phi_{\mathrm{c}}=15^{\circ} \mathrm{C} / \mathrm{min}$ are also shown. It is interesting to note that unlike $\Delta T_{p}$, the DTA data for $T_{\mathrm{n}}$ show a less dramatic change with $\Phi_{\mathrm{n}}$, although the changes are small, even for the DSC data. This may reflect a difference in sensitivity between the DTA and DSC or could indicate less surface nucleation and growth resulting from the superior sample atmosphere in the DSC, which has been improved

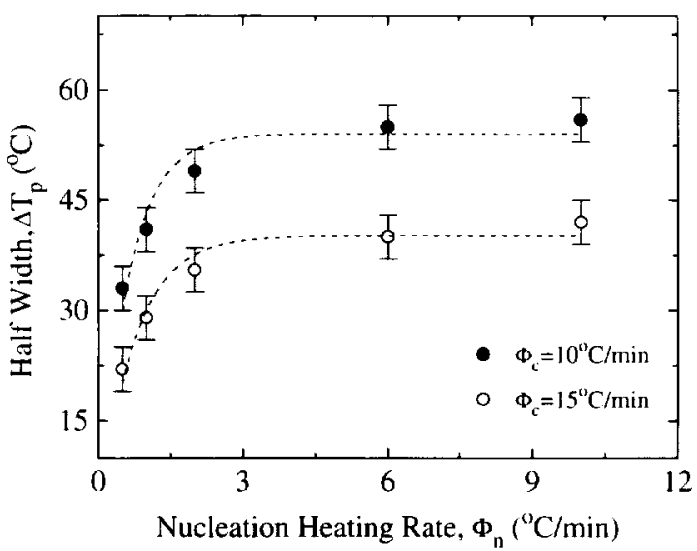

Fig. 5. DTA peak half-width for the crystallization of L.S2 glass powders $(425-500 \mu \mathrm{m}$ diameter) as a function of heating rate through the nucleation zone for two different values of crystallizat tion scan rate $\left(\Phi_{\mathrm{c}}=10^{\circ} \mathrm{C} / \mathrm{min}\right.$ and $\left.15^{\circ} \mathrm{C} / \mathrm{min}\right)$.

over that of the commercial instrument. As will be demonstrated in the companion paper [6], computer calculations are in better agreement with the DSC data. Taking $T_{\mathrm{p}}$ to be a weak function of $\Phi_{\mathrm{n}}$ for the same $\Phi_{\mathrm{c}}$, since $E$ for this glass is also independent of $\Phi_{n}$. Eq. (2) predicts that the dependence of $n$ on $\Phi_{\mathrm{n}}$ should be inversely related to that of $\Delta T_{\mathrm{p}}$ on $\Phi_{\mathrm{n}}$. The measured values of $\Delta T_{\mathrm{r}}$ and the corresponding values of $n$ calculated from Eq. (2) are shown as a function of $\Phi_{\mathrm{n}}$ for $\Phi_{\mathrm{c}}=10$ and $15^{\circ} \mathrm{C} / \mathrm{min}$ in Fig. 5 and Fig. 6, respectively. These show that for a

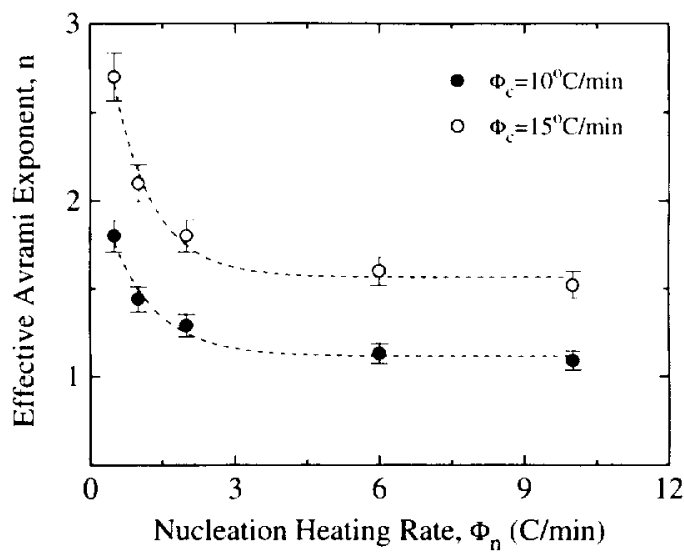

Fig. 6. Effective Avrami coefficient, $n$, for the crystallization of LS2 glass powders $(425-500 \mu \mathrm{m}$ diameter) as a function of heating rate through the nucleation zone for two different values of srystallization scan rate $\left(\Phi_{c}=10^{\circ} \mathrm{C} / \mathrm{min}\right.$ and $\left.15^{\circ} \mathrm{C} / \mathrm{min}\right)$. 
particular $\Phi_{c}, \Delta T_{p}$ increases and $n$ decreases with increasing $\Phi_{n}$ up to $3^{\circ} \mathrm{C} / \mathrm{min}$, suggesting a reduced dimensionality for crystal growth. As will be shown, this is due to the dominance of surface over volume growth. For values of $\Phi_{\mathrm{n}}$ greater than $3^{\circ} \mathrm{C} / \mathrm{min}$, both $\Delta T_{\mathrm{p}}$ and $n$ are independent of $\Phi_{\mathrm{n}} ; n$ is close to 1 indicating the increased importance of surface crystallization. The functional form of $\Delta T_{n}$ and $n$ with $\Phi_{n}$ is the same as that found for the DTA peak height. $(\delta T)$, (Fig. 1), although the direction of change is opposite for $\Delta T_{\mathrm{r}}$. The same general conclusions, namely, the formation of internal nuclei at sufficiently slow heating rates and the existence of a critical heating rate $\left(3^{\circ} \mathrm{C} / \mathrm{min}\right)$ above which no significant number of new nuclei form in the LS2 glass can therefore be inferred. The value of $n$ at each $\Phi_{n}$ is higher for higher $\Phi_{c}$. (compare $n$ for $\Phi_{c}=10$ and $15^{\circ} \mathrm{C} / \mathrm{min}$ in Fig. 6), which is, again, probably because a higher $\Phi_{c}$ pushes the transformation to a higher temperature, where the growth rate is larger, increasing the importance of the volume transformation.

As is illustrated in Fig. 7, the importance of surface crystallization can be observed directly from a study of the crystallization microstructure. Fig. 7(a) shows an optical micrograph of a portion of an LS2 glass that has been crystallized at $675^{\circ} \mathrm{C}$ for $2 \mathrm{~h}$. Here, surface crystallization is dominant, observed as a shell growing radially from the surface. This and the primarily amorphous region in the upper part of Fig. 7(a) indicates a much larger surface nucleation rate than a volume nucleation rate. Fig. 7(b) shows an optical micrograph of a LS2 glass containing 0.005 wt $\%$ Pt that has been crystallized under the same conditions. The thinner surface crystal layer and the fine grain size in the volume of the sample reflect the larger heterogeneous nucleation rate on the Pt particles. As discussed, the results from the DTA measurements are consistent with these SEM studies.

\subsection{Effect of glass particle size and nucleating agents}

The DTA peak heights, $\delta T_{\Gamma}$, measured at $15^{\circ} \mathrm{C} / \mathrm{min}$ for $40 \mathrm{mg}$ samples of as-quenched LS2 glass are shown as a function of the size of the glass particles in Fig. 8 The decrease in $\delta T_{\mathrm{p}}$ with increasing particle size suggests that small particles of
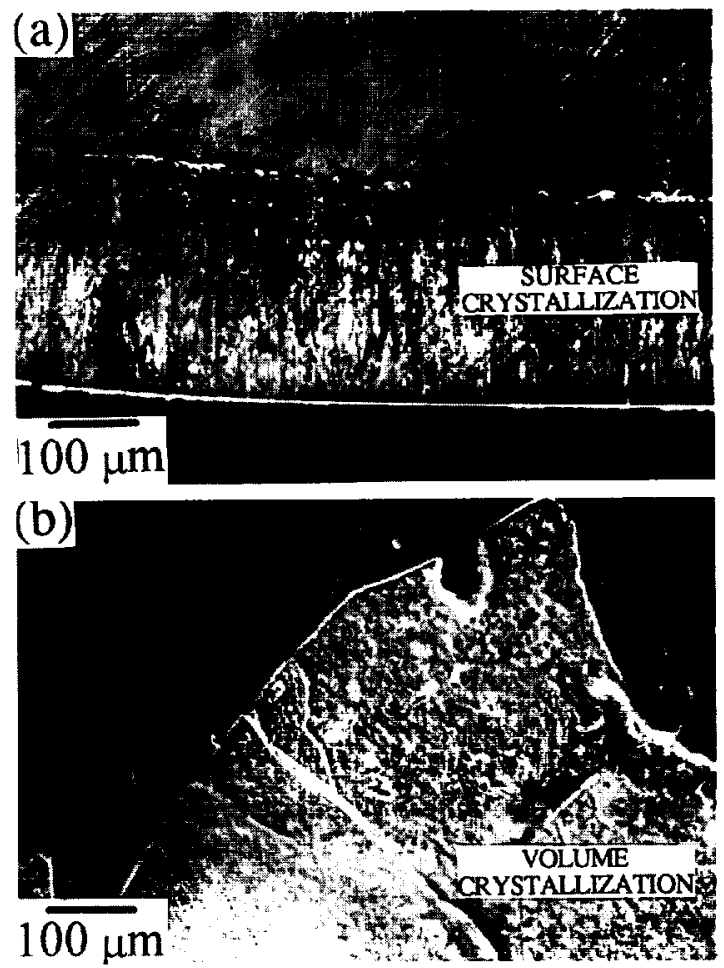

Fig. 7. Optical micrographs of partially crystallized LS2 glass showing (a) primarily surface crystallization in undoped glasses and (b) primarily volume erystallization in glasses doped with Pt.

as-quenched, non-nucleated LS2 glass crystallize primarily by surface crystallization. The number of internal nuclei should scale approximately with the

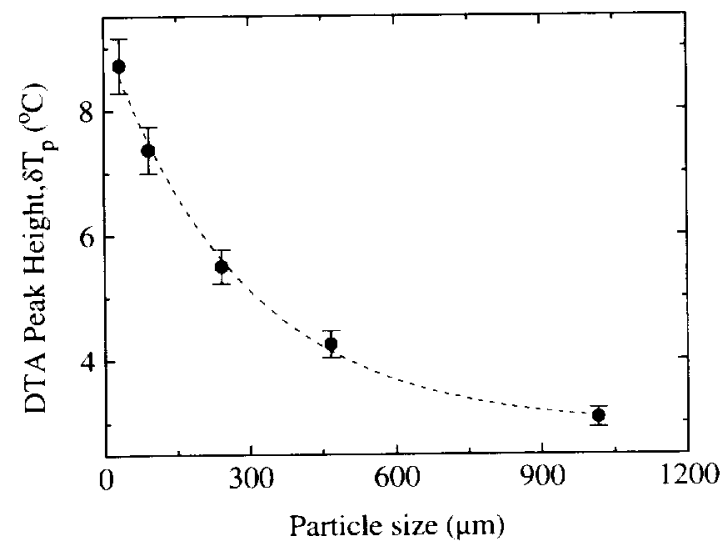

Fig. 8. DTA peak height for the crystallization of LS2 glass as a function of particle size. A constant heating rate of $15 \mathrm{C} / \mathrm{min}$ was used. 
volume of the particle. Based on the experience that $\delta T_{\mathrm{p}}$ is proportional to the number of nuclei [8], then, no change should be observed as a function of particle size (for the same scan conditions and the same mass of sample), if the transformation proceed only by internal nucleation and growth (assuming the absence of finite particle size effects which are discussed in Ref. [6]). The surface to volume ratio increases with decreasing particle size, however. For the same sample mass, an ensemble of smaller particles will contain considerably more surface area, and therefore an increasing number of surface nuclei with decreasing particle size, leading to the observed functional dependence.

To further investigate the competition between surface and volume crystallization in this LS2 glass. these measurements were repeated for LS2 glasses containing 0.001 and $0.005 \mathrm{wt} \%$ platinum added as a heterogeneous nucleating agent. Platinum-nucleated glasses are expected to crystallize primarily by internal nucleation and growth. The Pt particles catalyze the nucleation of the crystalline phase, dramatically increasing the nucleation rate. This causes the Ptdoped glasses to show a larger DTA peak height upon crystallization from the same sample amounts used for the undoped glass $(40 \mathrm{mg}$ ), making the temperature of the DTA furnace unstable. For example, a $40 \mathrm{mg}$ sample of the LS2 glass composed of $462 \mu \mathrm{m}$ average size particles and containing 0.005 wt\% Pt gave a DTA peak height that was larger than $40^{\circ} \mathrm{C}$ when scanned at $15^{\circ} \mathrm{C} / \mathrm{min}$. The sample weight was adjusted therefore according to platinum content so that the DTA peak height should not exceed 8 to $10^{\circ} \mathrm{C}$ when the glass composed of $462 \mu \mathrm{m}$ particles wals scanned at $15^{\circ} \mathrm{C} / \mathrm{min}$. This amount of glass was then maintained constant for the measurements on other particle sizes. The weights used were approximately $15 \mathrm{mg}$ for the $0.005 \mathrm{wt} \%$ Pt-doped glass and $20 \mathrm{mg}$ for the $0.001 \mathrm{wt} \% \mathrm{Pt}$-doped ones.

A direct comparison of $\delta T_{\mathrm{p}}$ among glasses was difficult since the magnitude of $\delta T_{\mathrm{p}}$ is a function of the amount and the dopant level of the glass. A reduced peak height, $\delta T_{\mathrm{p}}^{\mathrm{R}}$ was therefore used:

$\delta T_{\mathrm{P}}^{\mathrm{R}}=\frac{\delta T_{\mathrm{P}} \text { for a particular particle size }}{\delta T_{\mathrm{F}} \text { for the smallest particle size used }}$.

Here. the smallest particles were of order $35 \mu \mathrm{m}$ in size. The reduced peak height maintains the same

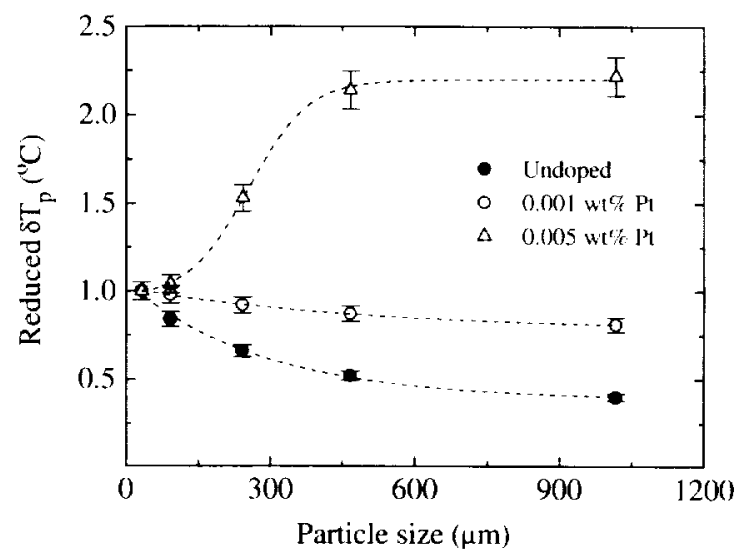

Fig. 9. Reduced DTA peak height for the crystallization of IS2 glass as a function of particle size for three different $\mathrm{Pt}$ dopant levels. A constant heating rate of $15^{\circ} \mathrm{C} / \mathrm{min}$ was used

functional trend as the original peak height with particle size, but makes possible a direct comparison between results for differently doped glasses. It is important to emphasize that the magnitude of $\delta T_{r}$ is also a function of $\mathrm{Pt}$ doping; this is factored out when Eq. (3) is used to plot the data sets for different doping levels.

The particle size dependence of $\delta T_{\mathrm{r}}^{\mathrm{R}}$ for the undoped LS2 glass and for glasses containing 0.001 and $0.005 \mathrm{wt} \% \mathrm{Pt}$ are compared in Fig. 9. Following Eq. (3). all values of $\delta T_{\mathrm{p}}$ are normalized to the value of $\delta T_{\mathrm{p}}$ for the $35 \mu \mathrm{m}$ diameter particles. These results indicate a competition between surface and internal nucleation and growth. Internal, or bulk. crystallization is dominant in the Pt-doped glasses. especially, for the glass containing $0.005 \mathrm{w} / \% \mathrm{Pt}$. There $\delta T_{\mathrm{p}}^{\mathrm{k}}$ increases with increasing particle size as opposed to the decreases observed in the undoped glass. For the glass containing $0.001 \mathrm{wt} \% \mathrm{Pt}, \delta T_{\mathrm{p}}^{\mathrm{R}}$ remains nearly unchanged with increasing particle size. In this case as the particle size increases the decrease in $\delta T_{\mathrm{p}}^{\mathrm{R}}$. corresponding to a decrease in the surface crystallization. is ncarly counterbalanced by the increase owing to the increasing internal crystallization due to platinum. These conclusions are supported by results obtained from computer simulations studies as a function of $\mathrm{Pt}$ impurities, which are presented in our companion paper [6].

For all doped and undoped glasses, the crystallization peak temperature. $T_{\mathrm{p}}$, increased with increasing 


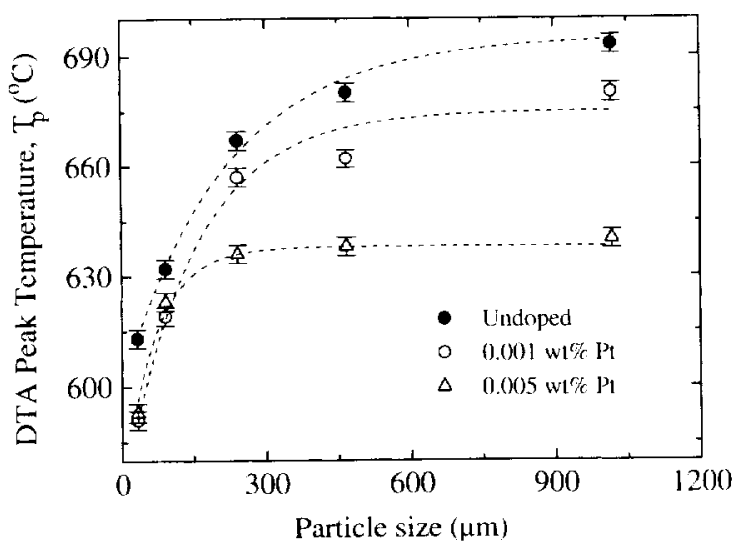

Fig. 10. DTA peak temperature for the crystallization of LS2 glass as a function of particle size for three different Pt dopant levels. A constant heating rate of $15 \mathrm{C} / \mathrm{min}$ was used.

particle size (Fig. 10). Fig. 10 also shows that for any particle size, $T_{\Gamma}$ decreases with increasing concentration of platinum in the glass, reflecting a lower stability against crystallization with increasing dopant level. Since all glasses have a similar behavior, however, the dependence of $T_{\mathrm{r}}$ on particle size, cannot readily provide information on the nature of the crystallization mechanism, i.e., whether it is surface or internal.

Although these changes in peak temperature as a function of particle size and Pt doping level might appear to be in contradiction with the results presented in Fig. 4, this simply reflects the simultaneous surface and volume crystallization. For small particles of undoped glasses, surface crystallization is the dominant mechanism (Fig. 7), quickly transforming the particles. The crystallization time at a given temperature increases with increasing particle size, however, due to the increasing importance of volume crystallization. As shown by the data in Fig. 10. for a non-isothermal scan, this has the effect of displacing the peaks to higher temperature, where the transformation rate is faster. All of the data in Fig. 4 were taken from large particles, $425-500 \mu \mathrm{m}$ in diameter, where volume crystallization is the dominant mechanism. The small changes in peak temperature with heating rate through the nucleation zone simply indicate that the change in the number of nuclei induced by the non-isothermal annealing was small. Correspondingly, the increased nucleation rate with $\mathrm{Pt}$ doping increases the volume transformation rate. thus lowering the transformation temperature. That a larger change in the peak temperature is observed for particles of similar size with $\mathrm{Pt}$ doping than with non-isothermal annealing in the nucleation zone simply reflects the high number and catalytic efficiency of the Pt impurities. That the change in peak temperature with particle size is less for the more heavily doped glasses reflects the increased volume transformation rate, now comparable with the surface crystallization rate (Fig. $7 b$ ).

As was discussed in Section 3.1., like $\delta T_{\Gamma}$ the peak half width, $\Delta T_{p}$, and the crystal growth dimension, $n$, can also be used to predict whether a glass transforms predominantly by surface or internal crystallization. From Eq. (2), $n$ is a function of $T_{p}, \Delta T_{F}$. and the activation energy for crystallization, $E$. Both $T_{\mathrm{p}}$ and $\Delta T_{\mathrm{p}}$ change with particle size and also with the platinum content in the glass. It is difficult, then. to estimate the particle size and Pt-doping dependence of $n$ solely from that of $\Delta T_{n}$. Rather, the dependence of $n$ should follow that of $T_{p}^{2} / \Delta T_{n}$ : since $E$ is approximately equal to the activation energy for growth, it should be relatively independent of particle size and Pt-doping. The parameter $\left[T_{\mathrm{p}}^{2} / \Delta T_{\mathrm{p}}\right]$ can therefore be used to identify surface or bulk crystallization. Values of $T_{\mathrm{p}}^{2} / \Delta T_{\mathrm{p}}$, were calculated from the measured values of $T_{p}$ and $\Delta T_{p}$. For a better comparison among the Pt-doped and undoped glasses, they were reduced in the same way as for $\delta T_{p}$, i.e..

$\left[\frac{T_{\mathrm{p}}^{2}}{\Delta T_{\mathrm{p}}}\right]^{\mathrm{R}}=\frac{T_{\mathrm{p}}^{2} / \Delta T_{\mathrm{p}} \text { for a particular particle size }}{T_{\mathrm{p}}^{2} / \Delta T_{\mathrm{p}} \text { for the smallest particle size used }}$.

Fig. 11 shows the plots of $\left[T_{p}^{2} / \Delta T_{p}\right]^{\mathrm{R}}$ as a function of particle size for all of the doped and undoped LS2 glasses. The functional dependence with particle size resembles closely that of the reduced $\delta T_{p}, \delta T_{\mathrm{p}}^{\mathrm{R}}$ (Fig. 9). Thus, like $\delta T_{\mathrm{p}}^{\mathrm{R}},\left[T_{\mathrm{p}}^{2} / \Delta T_{\mathrm{p}}\right]^{\mathrm{R}}$ also indicates that surface crystallization dominates in the undoped LS2 glass, while internal crystallization becomes dominant in the Pt-doped glasses (see Fig. 7). 


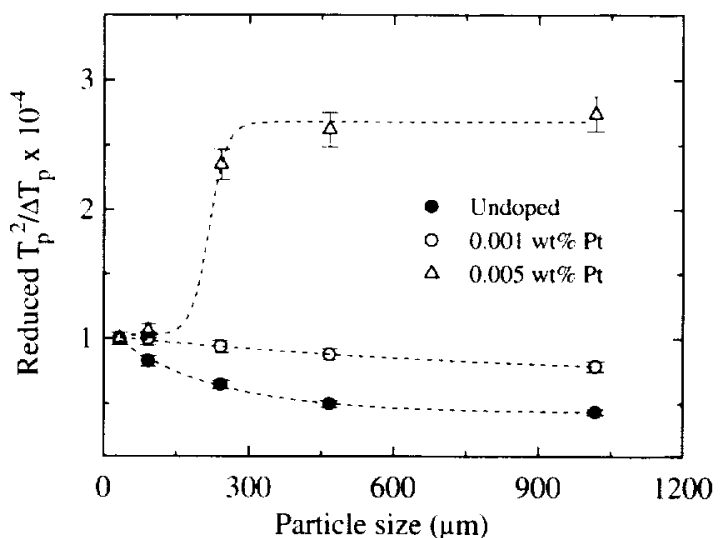

Fig. 11. Reduced parimeter $\left(T_{\mathrm{p}}^{2} / \Delta T_{1}\right)$ for the crystallization of LS2 glass as a function of particle size for three different $\mathrm{Pt}$ dopant levels, A consiant heating rate of $15^{\circ} \mathrm{C} / \mathrm{min}$ was used.

\subsection{Effects of water content}

As was discussed in Section 2, this investigation was extended further by deliberately changing the surface characteristics of the glass particles, exposing some samples to a moist atmosphere (wet samples) and annealing others in a dry environment (dry samples). Samples were subsequently scanned at $15^{\circ} \mathrm{C} / \mathrm{min}$ in the DTA. Fig. 12 compares values of $\delta T_{\mathrm{p}}$. from $40 \mathrm{mg}$ of the wet and dry samples as a function of particle size. Clearly, the effect of surface crystallization on $\delta T_{p}$ is larger in the wet sam-

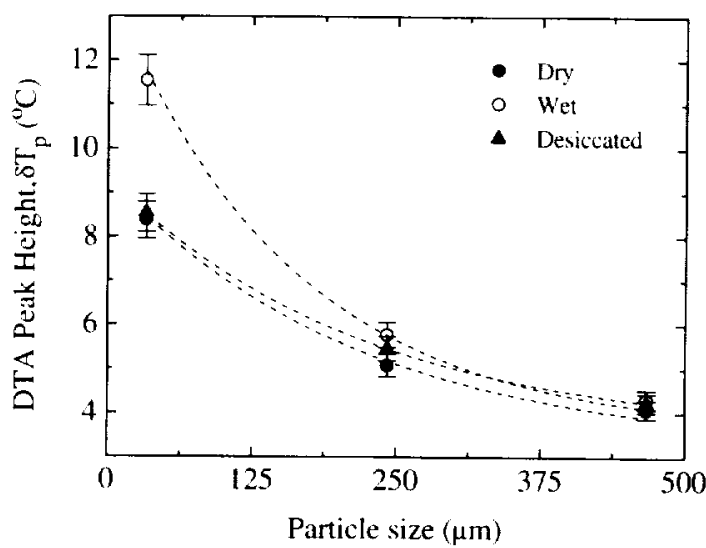

Fig. 12. DTA peak height for the crystallization of LS2 glass as a function of particle size for glasses exposed to atmospheres of dlifferent water content. All particles were heated at a constant rate of $15 \mathrm{C} / \mathrm{min}$.

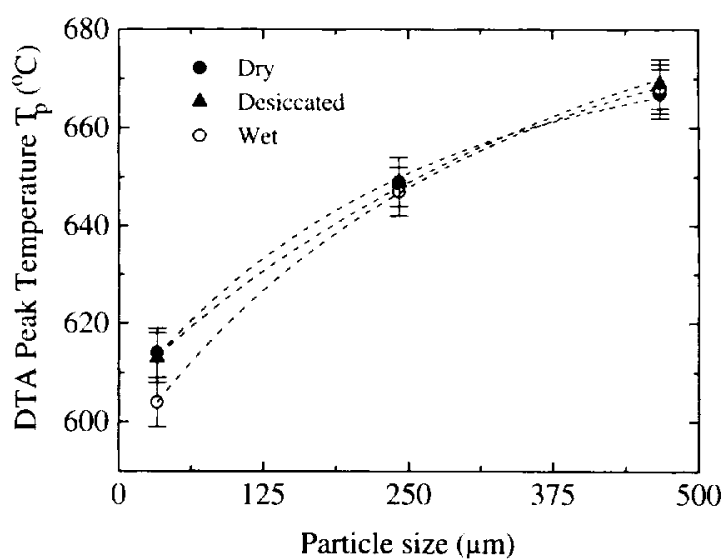

Fig. 13. DTA peak temperature for the crystallization of LS2 glass as a function of particle size for glasses exposed to atmospheres of different water content. All particles were heated at a constant rate of $15^{\circ} \mathrm{C} / \mathrm{min}$.

ples, Further, the effect is greater for the smaller particles, where the surface to volume ratio is larger. These results are consistent with the known effect that water increases the atomic mobility in LS2 glass $[18,19]$. The surface growth rate will be increased up to the point corresponding to the diffusion depth of the water. Since this distance is the same for the smaller and larger particles, the surface crystallization will be accelerated proportionally more for the smaller particles. For comparison, the dependence of $\delta T_{\mathrm{p}}$ on particle size for the glass stored in a vacuum desiccator (solid triangles) is also shown. The curve for the glass stored in the vacuum desiccator is very close to that for the dry glass, indicating that as expected, storing in a vacuum desiccator keeps this glass reasonably dry.

As for the glasses doped with platinum, the dependence of $T_{\mathrm{p}}$ on particle size for the wet and dry glasses fails to provide any information concerning the dominant crystallization mechanism (Fig. 13). The values of $T_{p}$ for the wet and dry glasses are nearly indistinguishable. They increase with increasing particle size indicating only an increased resistance to crystallization as the particle size increases. On the other hand, $T_{\mathrm{p}}^{2} / \Delta T_{\mathrm{p}}$ for the wet and dry glasses shows a functional dependence (Fig. 14) similar to that of $\delta T_{\mathrm{p}}$ (Fig. 12), and is considered to be a more useful parameter for understanding the crystallization mechanism in glasses. Since hydrating 


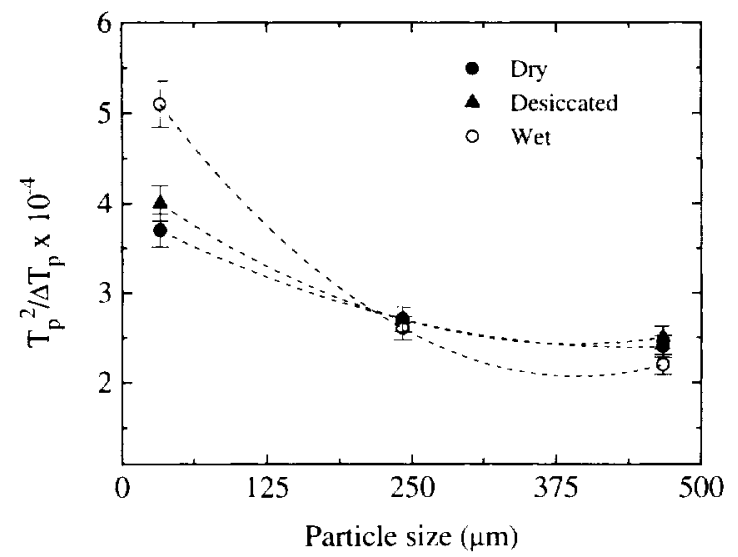

Fig. 14. Reduced parameter $\left(T_{p}^{2} / \Delta T_{p}\right)$ for the crystallization of LS2 glass as a function of particle size for glasses exposed to atmospheres of different water content. A constant heating rate of $15^{\circ} \mathrm{C} / \mathrm{min}$ was used.

is known to change the growth rate in these glasses, $E$ is likely not constant, making interpretations of the transformation mechanism using Eq. (2) difficult.

\section{Conclusions}

In summary, we have demonstrated that glasses heated through a temperature range where there is significant nucleation can develop widely different numbers of nucleated clusters. As expected, the nuclei concentration increases with a decreasing heating rate. This must be taken into account during glass processing since samples subjected to different heating rates may have widely different characteristics. We have also shown that non-isothermal DTA experiments can be used to study these effects. Based on studies of one glass, there is a characteristic critical heating rate, $\Phi_{n}{ }^{*}$, above which no significant nucleation occurs; this is an expected result from steady-state nucleation considerations. This value will be different for different glasses and different particle sizes; for the $462 \mu \mathrm{m}$ diameter particles of lithium disilicate glass studied, $\Phi_{\mathrm{n}}^{*}=3^{\circ} \mathrm{C} / \mathrm{min}$. We have argued that transient effects are important for a quantitative understanding of the effects of isothermal and non-isothermal annealing treatments on DSC/DTA transformation behavior. This will be demonstrated more fully in the companion paper [6].
DTA experiments also provide a convenient, fast, method for examining the relative importance of surface or internal crystallization. Based on DTA and microscopy experiments, it has been shown in the present investigation that lithium disilicate glasses crystallize primarily by surface crystallization. The importance of surface crystallization can be enhanced by the deliberate exposure of the glass particles to a moist atmosphere. Internal nucleation can be enhanced by the introduction of nucleating agents, such as Pt particles. When the glass is doped with platinum, internal crystallization appears to dominate over surface crystallization as the platinum concentration exceeds $0.001 \mathrm{wt} \%$ in this LS2 glass.

Finally, we have made the first systematic studies of the effects of particle size on the crystallization behavior. Most of these effects appear to be explained by the relative importance of surface versus internal crystallization. A computer model that allows a realistic analysis of these non-isothermal DTA data and an exploration of finite size effects is presented in a companion paper [6].

\section{Acknowledgements}

The authors thank M.C. Weinberg for useful discussions. This work was partially supported by NASA under contracts NAG 8-873, NAG 8-898 and NCC-849.

\section{References}

[1] K.F. Kelton and F. Spaepen, Acta Metall. 33 (1985) 455.

[2] J.C. Holzer and K.F. Kelton. Acta Metall. 39 (1991) 1833

[3] H. Yinnon and D.R. Uhlmann, J. Non-Cryst. Solids 54 (1983) 253.

[4] M.C. Weinberg, J. Non-Cryst. Solids 127 (1991) 151.

[5] K.F. Kelton, J. Non-Cryst, Solids 163 (1993) 283.

[6] K.F. Kelton, K.L. Narayan. L.F. Levine. T.C. Cull and C.S Ray, this issue p. 13

[7] P.F. James. Phys. Cham. Glasses 15 (1974) 95

[8] C.S. Ray and D.E. Day, J. Am. Ceram. Soc. $73(1990) 439$

[9] D.W. Henderson. J. Non-Cryst. Solids 30 (1979) 301.

[10] H.E. Kissinger. J. Res. Nat. Bur. Stand. (US) 57 (1956) 217 ; Anal. Chem. 29 (1957) 1702.

[11] R.A. Grange and J.M. Kiefer. Trans. ASM 29 (1941) 85

[12] P.I.K. Onorato and D.R. Uhlmann, JNCS 22 (1976) 367

[13] K.F. Kelton and A.L. Greer. J. Non-Cryst. Solids 79 (1986) 295. 
[14] X.J. Xu. C.S. Ray and D.F. Day, J. Am. Ceram. Soc, 74 (1991) 909 .

[15] C.S. Ray and D.E. Day. Ceram. Trans. 30 (1993) 207.

[16] M.T. Barker, T.H Wang and P.F. James. Phys. Chem. Glasses $29(1988) 240$.

[17] J.A. Augis and J.E. Bennett. J. Therm. Anal. 13 (1978) 283.
[18] P.F. James, B. Scott and P. Armstrong, Phys. Chem. Glasses 19 (1978) 24: C.J.R. Gonzalez-Oliver, P.S. Johnson and P.F. James. J. Mater. Sci. $14(1979) 1159$.

[19] P.F. James, in: Glasses and Glass Ceramics. ed. M.H. Lewis (Chapman and Hall, New York. 1989) p. 59. 


\section{Journal of Non-Crystalline Solids}

\section{Instructions to Authors}

Submission of papers

Manuscripts (one original + two copies), should be sent to the editors or any one of the regional editors. The address of the editors is as follows:

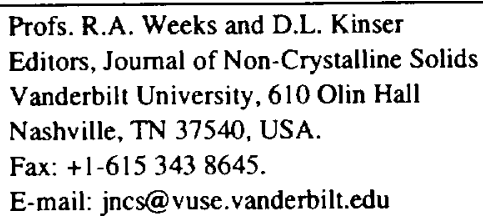

Original material: On submission, authors are asked to confirm that the manuscript is not being simultaneously considered for publication elsewhere and that all authors have approved the manuscript and take full responsibility for its contents and so state in their letter of transmittal.

\section{Types of contributions}

Original research papers, reviews, letters to the editor and commentaries are welcome. They should contain an Abstract (of up to 200 words) and a Conclusions section which, particularly in the case of theoretical papers, translates the results into terms readily accessible to most readers.

Letters should be no longer than six double-spaced typed pages. They will be given priority in both the refereeing and production processes. The faster production schedule will preclude sending proofs of letters to authors.

\section{Manuscript preparation}

All manuscripts should be written in good English. The paper copies of the text should be prepared with double line spacing and wide margins, on numbered sheets. See notes opposite on electronic version of manuscripts.

Structure. Please adhere to the following order of presentation Article title, Author(s), Affiliation(s), Abstract, PACS codes, Main text (Introduction; Experimental procedures or constraints on theory; Results; Discussion; Conclusion. Sections and sub-sections must be clearly numbered according to the Joumal style). Acknowledgements, Appendices, References, Figure captions, Tables. Corresponding author. The name, complete postal address, telephone and fax numbers and the e-mail address of the corresponding author should be given on the first page of the manuscript.

References. References to other work should be consecutively numbered in the text using square brackets and listed by number in the Reference list. Please refer to past issues of the Joumal for examples.

Symbols/Units: Authors should follow the Symbols and Units Nomenclature Commission of the 1.U.P.A.P. (Physica 146A (1987) $1-68)$.

\section{Illustrations (figures)}

Illustrations should also be submitted in triplicate: one master set and two sets of copies. The line drawings in the master set should be original laser printer or plotter output or drawn in black india ink, with careful lettering; lettering should $2 \mathrm{~mm}$ in height after reduction for printing. The photographs should be originals, with somewhat more contrast than is required in the printed version. The top edge should be indicated on the back. They should be unmounted unless part of a composite figure. Any scale markers should be inserted on the photograph itself, not drawn below it.
Colour plates. Figures may be published in colour, if this is judged essential by the editor. The publisher and the author will each bear part of the extra costs involved. Further information is available from the publisher.

\section{Classification codes/keywords}

Please supply one to four classification codes (PACS and/or MSC) and up to six keywords of your own choice that describe the content of your article in more detail.

\section{After acceptance}

Notification. You will be notified by the Editor of the journal of the acceptance of your article and invited to supply an electronic version of the accepted text, if this is not already available.

Copyright sransfer. In the course of the production process you will be asked to transfer the copyright of the article to the publisher. This transfer will ensure the widest possible dissemination of information.

IMPORTANT: When page proofs of the accepted manuscript are made and sent to authors, this is in order to check that no undetected errors have arisen in the typesetting (or file conversion) process. Only printers' errors may be corrected; no changes in, or additions to, the edited manuscript will be accepted. In the case of extended changes, the authors will be required to pay part of the extra costs involved.

\section{Electronic manuscripts}

The publisher welcomes the receipt of an electronic version of your accepted manuscript. If there is not already a copy of this (on diskette) with the joumal editor at the time the manuscript is being refereed, you will be asked to send a file with the text of the accepted manuscript directly to the Publisher by e-mail or on diskette (allowed formats $3.5^{\circ}$ or $5.25^{\circ}$ MS-DOS, or $3.5^{\circ}$ Macintosh) to the address given below. Please note that no deviations from the version accepted by the Editor of the joumal are permissible without the prior and explicit approval by the Editor. Such changes should be clearly indicated on an accompanying printout of the file.

\section{Author benefits}

No page charges. Publishing in Journal of Non-Crystalline Solids is free.

Free offprints. The corresponding author will receive 50 offprints free of charge. An offprint order form will be supplied by the publisher for ordering any additional paid offprints.

Discount. Contributors to Elsevier Science journals are entitled to a $30 \%$ discount on all Elsevier Science books.

Further information (after acceptance)
Elsevier Science B. Y.

Journal of Non-Crystalline Solids

Issue Management

P.O. Box 2759, 1000 CT Amsterdam

The Netherlands.

Fax: +31204852319

E-mail: g.anderton@elsevier.nl 
